\title{
A Importância da Hospitalidade em Unidades de Saúde: Um Estudo de Caso no Hospital Municipal Ruth Cardoso de Balneário Camboriú/SC
}

\section{The Importance of Hospitality in Health Units: A Case Study at the Municipal Hospital Ruth Cardoso of Balneário Camboriú/SC}

\author{
La Importancia de la Hospitalidad en Unidades de Salud: Un Estudio de Caso en el \\ Hospital Municipal Ruth Cardoso de Balneario Camboriú/SC
}

Marina Tété Vieira ${ }^{1}$

Resumo: A hospitalidade exerce um diferencial na composição dos serviços prestados pelas unidades de saúde, garantindo aos usuários uma experiência diferenciada através das relações humanas. O objetivo desta pesquisa foi avaliar a hospitalidade no Hospital Municipal Ruth Cardoso, localizado em Balneário Camboriú/SC, de acordo com os parâmetros da filosofia Planetree. Este estudo de caso de caráter exploratório adotou como método a revisão bibliográfica, a análise documental, a coleta das informações através de questionários e a observação. A análise foi qualitativa com base nos referenciais adotados e na percepção das pesquisadoras, construída através do percurso metodológico. Como resultado, verificamos que o hospital não está de acordo com muitos dos parâmetros da filosofia Planetree.

Palavras-Chave: Hospitalidade, Unidades de Saúde, Filosofia Planetree.

Abstract: The hospitality has a differential in the composition of services provided by health units, ensuring for the users a differentiated experience through human relations. The objective of this research was to evaluate the hospitality at the Hospital Municipal Ruth Cardoso, located in Balneário Camboriú/SC, according to the parameters of the Planetree philosophy. This exploratory case study adopted as a method the bibliographic review, the documentary analysis, the collection of information through questionnaires and observation. The analysis was qualitative based on the adopted references and the perception of the researchers, built through the methodological path. As a result, we find that the hospital does not agree with many of the parameters of the Planetree philosophy.

Key words: Hospitality, Health units, Planetree philosophy.

Resumen: La hospitalidad ejerce un diferencial en la composición de los servicios prestados por las unidades de salud, garantizando a los usuarios una experiencia diferenciada a través de las relaciones humanas. El objetivo de esta investigación fue evaluar la hospitalidad en el Hospital Municipal Ruth Cardoso, ubicado en Balneário Camboriú / SC, de acuerdo con los parámetros de la filosofia Planetree. Este estudio de caso de carácter exploratorio adoptó como método la revisión bibliográfica, el análisis documental, la recolección de las informaciones a través de cuestionarios y la observación. El análisis fue cualitativo con base en los referenciales adoptados y en la percepción de las investigadoras, construida a través del recorrido metodológico. Como resultado, verificamos que el hospital no está de acuerdo con muchos de los parámetros de la filosofía Planetree.

Palabras clave: Hospitalidad, Unidades de salud, Filosofía Planetree.

\footnotetext{
${ }^{1}$ Meste em Turismo e Hotelaria e Doutoranda em Turismo e Holetaria pela Universidade do Vale do Itajaí. Docente do Eixo de Turismo, Hospitalidade e Lazer no Instituto Federal Catarinense - Camboriú. E-mail: marina.vieira@ifc.edu.br.
} 
VIEIRA, M. T. A Importância da Hospitalidade em Unidades de Saúde: um estudo de caso no Hospital Municipal Ruth Cardoso de Balneário Camboriú/SC. Revista Hospitalidade. São Paulo, volume 16, n.02, p. 3-30, 2019. Doi: https://doi.org/10.21714/21799164.2019.v16n2.001.

\section{Introdução}

O presente estudo trata da hospitalidade no Hospital Municipal Ruth Cardoso, localizado em Balneário Camboriú/SC, eleito como objeto de estudo por ser o único hospital público que atendia, até a data da realização da coleta de dados (ano de 2018), os usuários do Sistema Único de Saúde de Balneário Camboriú/SC e Camboriú/SC, sua cidade vizinha. O hospital foi inaugurado em 2008, porém foi aberto ao público quatro anos depois. Sua estrutura conta com 115 leitos e é administrada pela organização Cruz Vermelha Brasileira. Segundo a coordenadora de hotelaria hospitalar da referida unidade de saúde (2017), atualmente o hospital realiza, em média, 250 atendimentos por dia, resultando em, aproximadamente, 7500 atendimentos por mês.

A hospitalidade possui conceitos antigos que perpassam o setor de hotelaria, contemplando todas as áreas de atendimento ao público. Segundo Mascarenhas e Souza (2015, p. 11), "o termo hospitalidade se refere ao gesto de acolher alguém, tanto em casa quanto em outros locais", Camargo (2004), por sua vez, afirma que dar, receber e retribuir são também os três deveres que funcionam como uma chave que orienta as relações sociais nas sociedades arcaicas.

$\mathrm{Na}$ atualidade, a hospitalidade, tanto nos hotéis quanto nos hospitais, apesar das significativas diferenças entre seu público e a missão a que se propõem, configura-se como aspecto ímpar na constituição destes dois ambientes. É a hospitalidade, com seu caráter mais autêntico, mais genuíno, que deve estar presente nas relações de troca de experiências e prestação de serviços nestas organizações.

Para tanto, levando em consideração o fato de que os hospitais são um sistema complexo, onde um setor e as pessoas que dele fazem parte exercem influência sobre os demais, deverão ser pensados e estruturados no sentido de oferecer um diferencial em relação aos demais. Esse diferencial, que pode ser a hospitalidade, conforme será apresentado no decorrer deste estudo, não é só mais um diferencial, mas uma exigência para as instituições de saúde, que precisam considerar não só a técnica, mas também o lado humano da internação.

É justamente no contexto da hospitalidade que se baseia o Planetree, filosofia aplicada e disseminada no Brasil através do Hospital Israelita Albert Einstein, localizado no estado de São Paulo. Esta filosofia tem o intuito de garantir a presença da hospitalidade na gestão organizacional dos hospitais associados. 
VIEIRA, M. T. A Importância da Hospitalidade em Unidades de Saúde: um estudo de caso no Hospital Municipal Ruth Cardoso de Balneário Camboriú/SC. Revista Hospitalidade. São Paulo, volume 16, n.02, p. 3-30, 2019. Doi: https://doi.org/10.21714/21799164.2019.v16n2.001.

Os hospitais são locais onde enfermidades são tratadas e, por este motivo, precisam de uma gerência diferenciada dos outros tipos de organizações, visando a cura do paciente como uma missão, proporcionando-lhe serviços hospitaleiros essenciais que contribuam efetivamente para sua cura. Sendo assim, o objetivo geral desta pesquisa foi avaliar a hospitalidade no Hospital Municipal Ruth Cardoso, localizado na cidade de Balneário Camboriú/SC ,de acordo com os indicadores do Planetree:

O estudo reforça que todas as novas tecnologias da área médica não podem fazer com que o funcionário de saúde se esqueça do "[..] único objetivo de toda a atividade hospitalar: ser um serviço para seres humanos!”, (MEZOMO, 2001, apud QUEVEDO, 2006, p. 35). É dentro desta discussão que esta pesquisa se insere e justifica sua importância como estudo acadêmico.

\section{Referencial teórico}

\section{Hospitalidade e a Hotelaria Hospitalar}

Para Camargo (2004, p.16), “o contato humano não se estabelece como uma troca [...] Começa com uma dádiva que parte de alguém para alguém. A retribuição é uma nova dádiva que implica um novo receber e retribuir, gerando dons e contra dons, num processo sem fim”.

Mauss (2003), em sua obra "Sociologia e antropologia", dedica uma parte desta, para falar da dádiva presente nos processos de troca nas civilizações arcaicas, quando o receber estava intrínseco ao dar, e o retribuir, ao receber. Nessas civilizações, segundo este autor, "recusar dar, negligenciar convidar, assim como recusar receber, equivale a declarar guerra; é recusar a aliança e a comunhão" (MAUSS, 2003, p. 202).

Para Lashley e Morrison (2004, p. 5) "a hospitalidade pode ser concebida como um conjunto de comportamentos originários da própria base da sociedade". Para os autores, em uma definição mais ampla, a hospitalidade pode ser manifestada nos domínios "social", "privado" e "comercial".

O domínio social da hospitalidade considera os cenários sociais em que a hospitalidade e os atos ligados, condição de hospitalidade ocorrem junto com os impactos de forças sociais sobre a produção e o consumo de alimentos, bebidas e acomodações. O domínio privado considera o âmbito das questões associadas da "trindade" no lar, assim como leva em consideração o impacto do relacionamento entre anfitrião e hóspede. O domínio comercial diz respeito à oferta de hospitalidade enquanto atividade econômica e inclui as atividades dos setores tanto privado quanto público. (LASHLEY e MORRISON, 2004, p. 5-6) 
VIEIRA, M. T. A Importância da Hospitalidade em Unidades de Saúde: um estudo de caso no Hospital Municipal Ruth Cardoso de Balneário Camboriú/SC. Revista Hospitalidade. São Paulo, volume 16, n.02, p. 3-30, 2019. Doi: https://doi.org/10.21714/21799164.2019.v16n2.001.

Quando se trata de hospitalidade, Camargo (2004) informa que existe a tendência de se criarem dois eixos de tempo/espaço para delimitar o campo de estudo entre eixo cultural e eixo social. O eixo cultural são as ações que abrangem a noção de hospitalidade em recepcionar ou receber pessoas, hospedar, alimentar e entreter. O eixo social, por sua vez, diz respeito aos modelos de interação social e circunstâncias físicas ambientais envolvidas. A hospitalidade pode ser definida como um ato humano, exercido nos três espaços: doméstico, público ou profissional, nos atos de recepcionar, hospedar, alimentar e entreter pessoas temporariamente deslocadas de seu habitat (CAMARGO,2004).

Nos hospitais, o setor de hospitalidade integra a equipe de hotelaria hospitalar com o objetivo de diferenciar os serviços prestados, atender bem e encantar o cliente. A hospitalidade oferecida pelo hospital tem em sua missão um conjunto de valores, modelos e ações que dizem respeito ao receber humano. (RIBEIRO, 2013).

De acordo com Godoi (2008), a hotelaria hospitalar é a introdução de técnicas, procedimentos e serviços de hotelaria em hospitais como consequente benefício social, físico, psicológico e emocional para pacientes, familiares e funcionários de um hospital. Já para Taraboulsi (2004, p. 179), a Hotelaria Hospitalar se conceitua como "a arte de oferecer serviços eficientes e repletos de presteza, alegria, dedicação e respeito, fatores que geram a satisfação, o encantamento do cliente de saúde e, principalmente, a humanização do atendimento e do ambiente hospitalar", acrescentando que esta ação implica a criação, a inserção e a adaptação de vários departamentos de hotelaria" na organização hospitalar.

Até antes de 1780, os hospitais configuravam-se como locais de assistência aos pobres, uma vez que antes da cura, propriamente dita, cuidar dos pobres e enfermos era uma forma de salvação do espírito e era a missão dos hospitais. Até o século XVIII a experiência hospitalar estava excluída da formação médica (MEDEIROS, 2004). Essa situação começou a ser invertida no século XVIII, quando o médico passou a ter o reconhecimento da sociedade e o hospital evoluiu para uma instituição terapêutica (MEDEIROS, 2004).

Desde então, os hospitais vêm identificando-se com os preceitos da humanização do atendimento. Para Mirshawka (1994, p. 22), o hospital deve ser encarado sob a forma de uma instituição dotada de planta física, equipamento e organização adequados à recepção de pacientes em regime de internação como ao seu tratamento, a fim de devolvê-los à comunidade em 
VIEIRA, M. T. A Importância da Hospitalidade em Unidades de Saúde: um estudo de caso no Hospital Municipal Ruth Cardoso de Balneário Camboriú/SC. Revista Hospitalidade. São Paulo, volume 16, n.02, p. 3-30, 2019. Doi: https://doi.org/10.21714/21799164.2019.v16n2.001.

condições satisfatórias de saúde. Assim, a hospitalidade, no contexto do crescente interesse pela humanização das relações sociais, desponta como alicerce para as relações estabelecidas nas instituições de saúde, que passam a ter no tratamento dispensado aos clientes de saúde, um dos seus focos de atenção e de ação.

Frozé (2010, p. 38) menciona que ao se falar de hospitalidade em uma instituição hospitalar, "os termos mais utilizados seriam: paciente, que é o cliente externo e colaborador ao qual se retende que seja acolhido e recebido em seu local de trabalho e a estrutura física, tal como cliente". A autora (2010, p. 45) observou que ao se implantar a hotelaria hospitalar, verifica-se uma preocupação com o atendimento, o que gera valor aos serviços prestados”. Boeger (2003, p. 24), por sua vez, define a hotelaria hospitalar como sendo: "a reunião de todos os serviços de apoio, que associados aos serviços específicos, oferecem aos clientes internos e externos conforto, segurança e bem-estar durante seu período de internação".

\section{Hospitalidade e o atendimento humanizado em unidades de saúde}

Quando tratamos de hospitalidade e atendimento humanizado em hospitais devemos levar em conta pacientes, acompanhantes, visitantes e funcionários da instituição. Todos devem manter entre si uma relação saudável e necessitam de um ambiente propício para que a hospitalidade se faça presente.

O paciente é o principal usuário de uma instituição de saúde. Segundo Nogueira (2003, apud QUEVEDO, 2006, p. 26):

Ele é a razão de um hospital existir. É um cliente fragilizado pela situação, com sentimentos confusos, como medo, frustração, dor. Eles reagem de diferentes formas a esses sentimentos, o que faz com que cada paciente seja um cliente especial e único. Se pudesse escolher, um paciente jamais desejaria utilizar serviços hospitalares. Então, torna-se um desafio a prestação de serviços de qualidade a ele.

O ser humano, no contexto hospitalar, não pode ser considerado apenas como um doente, pois, na realidade, é um indivíduo que carrega consigo inúmeros sentimentos e precisa ser contemplado na sua totalidade. Neste sentido, os profissionais que possuem uma ligação direta com eles, precisam ter ciência da inevitabilidade de um trabalho em conjunto, onde apesar das diferentes áreas, todos busquem amenizar o sofrimento dos pacientes através de suas especialidades como uma missão da instituição.

Além de proporcionarem o tratamento e a cura, os hospitais devem visar o bem-estar dos que buscam pelos seus serviços, pois esta atitude traz uma contribuição para a própria melhora 
VIEIRA, M. T. A Importância da Hospitalidade em Unidades de Saúde: um estudo de caso no Hospital Municipal Ruth Cardoso de Balneário Camboriú/SC. Revista Hospitalidade. São Paulo, volume 16, n.02, p. 3-30, 2019. Doi: https://doi.org/10.21714/21799164.2019.v16n2.001.

da situação do paciente em seu estado emocional e, consequentemente, pode acelerar seu processo de cura.

Segundo Mascarenhas e Souza (2015, p. 430): "São os pequenos gestos, vindos de profissionais que estão envolvidos no tratamento, ou daqueles que prestam serviços de apoio dentro da instituição, que podem fazer a diferença durante a permanência do paciente no hospital". Somente quando observarmos os detalhes conseguimos compreender o valor de pequenas atitudes que promovem grandes resultados.

Segundo o site do Planetree (2015), a aplicação de uma metodologia que garanta a presença da hospitalidade em hospitais, favorece a recuperação de pacientes nas áreas física, mental, emocional, social e espiritual através da aplicação dos seus dez parâmetros na relação entre usuários e profissionais da unidade de saúde, sendo estes: Interações humanas: procura tornar a relação entre os profissionais, pacientes e familiares mais afetiva e ativa no tratamento através da preocupação e interesse pelo bem-estar dos usuários. Suporte à família e acompanhantes: influencia o envolvimento do ciclo social do paciente em sua recuperação através da liberdade no horário de visitas e convite para os familiares passarem a noite no hospital sempre que possível. Educação de pacientes, familiares e acompanhantes: são disponibilizadas bibliotecas oferecendo informações sobre saúde, medicina e terapias complementares e conferências sobre cuidados, tratamento de usuários e outros recursos educacionais para pacientes, familiares e colaboradores. Arquitetura e design - ambiente de cura: áreas físicas do hospital como estímulo à cura. Aspectos nutricionais: a nutrição capaz de ofertar ao paciente uma fonte de prazer e conforto. Arte, música e entretenimento: durante o processo hospitalar deve haver mecanismos de distração e divertimento. Espiritualidade: ao reconhecer a importância da espiritualidade na cura, o Planetree oferece suporte aos familiares e colaboradores com recursos internos. Toque humano: o contato físico diminuindo a ansiedade, a dor e o estresse. Terapias complementares: aromaterapia, acupuntura, Reiki, Tai Chi, toque terapêutico e Ioga são algumas das opções oferecidas além das modalidades clínicas de tratamento. Comunidades: o envolvimento com escolas, centros de terceira idade, igrejas e outras instituições estimula a saúde e bem-estar a toda a sociedade local.

A angústia e ansiedade provocada por internações prolongadas podem ser aliviadas com atividades planejadas, voltadas para a humanização no atendimento e resgate dos valores 
VIEIRA, M. T. A Importância da Hospitalidade em Unidades de Saúde: um estudo de caso no Hospital Municipal Ruth Cardoso de Balneário Camboriú/SC. Revista Hospitalidade. São Paulo, volume 16, n.02, p. 3-30, 2019. Doi: https://doi.org/10.21714/21799164.2019.v16n2.001.

culturais. Pode - se buscar o favorecimento do convívio familiar, mediante atividades como artes plásticas, pintura e desenho, contos, história da arte, musicoterapia, jogos, literatura, trabalho corporal e artes folclóricas (GODÓI, 2008). Essa iniciativa constrói um relacionamento seguro e com qualidade com o hóspede proporcionando construções de vínculos, amenizando condições e potencializando os processos de produção de saúde (ROSSETO E BAPTISTA, 2016).

Diante disso Andrade (2011), indica que o atendimento humanizado em hospitais é percebido quando o paciente fragilizado em seu estado físico, psicológico e emocional, for atendido nas suas necessidades, angústias, dúvidas, questionamentos e se sinta em um ambiente que lhe deixe confortável, tranquilo, acolhido e seguro .

Na leitura de Godói (2008, p. 45), observa-se, por intermédio da humanização do ambiente, que "o restabelecimento do doente é maximizado num menor período de tempo, havendo ao final um sentimento de satisfação e realização para as equipes médicas e a administração perceberá os resultados". Nas palavras de Frozé (2010, p. 39), ao se "discutir a hospitalidade em hospitais tornou-se uma necessidade a vivência num ambiente organizacional cujos valores maiores incluem a humanização que podem trazer grandes benefícios para o indivíduo e para o grupo". A autora enfatiza a semelhança no termo humanização e hospitalidade, "quando as ações estão alinhadas com conceitos que permeiam a Hospitalidade" (FROZÉ, 2010, p. 36).

Portanto para Taraboulsi (2004, p.48).

(...) o triunfo da hotelaria hospitalar está na humanização do ambiente hospitalar: serviços eficientes que encantam, cores suaves, plantas e jardins bem cuidados e, principalmente, pessoas entusiasmadas interagindo com os clientes de saúde, revelando de tal forma o segredo dessa nova proposta que é o sorriso sincero e permanente, marca registrada da satisfação e do amor pelo trabalho realizado. Os clientes de saúde (enfermos, familiares, acompanhantes, visitantes) sentem-se confiantes e motivados quando a solidariedade apresenta -se estampada nos semblantes de todos os envolvidos em seu atendimento. É a humanização, através da hotelaria, mudando condutas e comportamentos.

Assim, a hospitalidade, no contexto do crescente interesse pela humanização das relações sociais, desponta como alicerce para as relações estabelecidas nas instituições de saúde, que passam a ter no tratamento dispensado aos clientes de saúde, um dos seus focos de atenção e de ação. 
VIEIRA, M. T. A Importância da Hospitalidade em Unidades de Saúde: um estudo de caso no Hospital Municipal Ruth Cardoso de Balneário Camboriú/SC. Revista Hospitalidade. São Paulo, volume 16, n.02, p. 3-30, 2019. Doi: https://doi.org/10.21714/21799164.2019.v16n2.001.

\section{Procedimentos metodológicos}

Para alcançarmos os objetivos da pesquisa, utilizamos a metodologia qualitativa de natureza exploratória e descritiva. Para Chizzotti (1995), a abordagem qualitativa parte do fundamento de que há uma relação dinâmica entre o mundo real e o sujeito, um vínculo indissociável entre o mundo objetivo e a subjetividade. Segundo Gil (2008, p. 26), "pesquisas exploratórias são desenvolvidas com o objetivo de proporcionar visão geral, de tipo aproximativo, acerca de determinado fato". De acordo com o mesmo autor (2008) as pesquisas descritivas possuem o objetivo de estudar as características de um grupo.

Nos aprofundamos no tema através de revisão bibliográfica e documental. Ao longo das reuniões, decidiu-se realizar um estudo de caso no Hospital Municipal Ruth Cardoso, sendo este o único hospital público do município de Balneário Camboriú/SC.

Após a delimitação do tema, entramos em contato com a Secretaria de Saúde de Balneário Camboriú/SC a fim de identificarmos a existência de documentos importantes que pudessem contribuir com o estudo proposto. Logo, iniciamos uma varredura em referenciais bibliográficos, em dissertações, teses e artigos, bem como em documentos reguladores, a fim de construir na construção da revisão de literatura.

De forma a contemplar a hospitalidade em todos os setores do hospital, optamos pela observação e aplicação de questionários semiestruturados para seis colaboradores: diretor-geral, coordenadora de atendimento, coordenador de enfermagem, coordenadora de hotelaria hospitalar, coordenadora de nutrição e coordenador de segurança do trabalho. Também definimos que a aplicação de questionários para os usuários seria realizada com cinco pacientes e cinco acompanhantes do Hospital Municipal Ruth Cardoso. O instrumento para a coleta das informações foi construído em consonância com os objetivos da pesquisa, referenciais estudados e parâmetros da filosofia Planetree. Após elaboração de oito questionários semiestruturados, com treze questões em média, os aplicamos com os coordenadores e usuários dos setores de obstetrícia e maternidade, cirurgia geral, clínica geral e pediatria, conforme mostra a Tabela 01.

A etapa de coleta de dados durou aproximadamente cinco semanas. Os dez questionários dos usuários e acompanhantes foram aplicados pessoalmente em três idas ao hospital, enquanto os seis questionários dos coordenadores e do diretor-geral foram deixados com os mesmos e com prazos preestabelecidos para serem entregues. 
VIEIRA, M. T. A Importância da Hospitalidade em Unidades de Saúde: um estudo de caso no Hospital Municipal Ruth Cardoso de Balneário Camboriú/SC. Revista Hospitalidade. São Paulo, volume 16, n.02, p. 3-30, 2019. Doi: https://doi.org/10.21714/21799164.2019.v16n2.001.

Em nossas visitas ao hospital utilizamos um roteiro de observação para analisarmos as áreas físicas dele, a fim de verificarmos se a hospitalidade é manifestada através da sua infraestrutura.

Os resultados obtidos foram tratados e analisados considerando os marcos teóricos do projeto e confrontados com os dez parâmetros do Planetree, resultando na proposta de um documento de conscientização e orientação para unidades de saúde.

Tabela 01 - Número de respondentes por setor

\begin{tabular}{lcc}
\hline \multicolumn{1}{c}{ Setor } & Pacientes entrevistados & Acompanhantes entrevistados \\
\hline Obstetrícia e maternidade & 3 & 1 \\
Cirurgia geral & 1 & 1 \\
Clínica geral & 1 & 1 \\
Pediatria & 0 & 2 \\
\hline
\end{tabular}

Fonte: dados da pesquisa (2019).

\section{Análise e discussões}

Para melhor compreensão, os resultados foram organizados por grupos de respondentes: No item 1 apontaremos as informações obtidas nos questionários dos pacientes que utilizaram os serviços da unidade de saúde; no item 2, indicaremos as respostas dos acompanhantes e no item 3 revelaremos as informações sob a perspectiva dos coordenadores e diretor-geral do hospital.

\section{Pacientes}

Foram entrevistados cinco pacientes que, para fins de análise, representarão $100 \%$ da amostra. Todos os participantes foram eleitos pela coordenadora de hotelaria hospitalar, que nos acompanhou em toda a etapa da coleta das informações. Os dados obtidos correspondem aos seguintes indicadores:

Entendimento acerca da hospitalidade: A hospitalidade é o ato de fazer alguém se sentir em casa através de um acolhimento afetuoso e uma estadia confortável. Conforme aponta Godoi (2008, p. 18):

O papel da hospitalidade é fundamental, especialmente em hotéis e hospitais que lidam com o ser humano e suas necessidades mais urgentes. A hospitalidade representa um papel-chave em tornar uma acolhida agradável e calorosa, mais que simplesmente satisfazer os desejos ou atender as necessidades de uma outra pessoa em deslocamento ou hospitalização. 
VIEIRA, M. T. A Importância da Hospitalidade em Unidades de Saúde: um estudo de caso no Hospital Municipal Ruth Cardoso de Balneário Camboriú/SC. Revista Hospitalidade. São Paulo, volume 16, n.02, p. 3-30, 2019. Doi: https://doi.org/10.21714/21799164.2019.v16n2.001.

Ao questionar os pacientes sobre os momentos em que a hospitalidade se faz presente no hospital, $20 \%$ declarou percebê-la através do contato com os funcionários, enquanto $20 \%$ destacou a percepção da hospitalidade na integração entre profissionais e usuários. Contrapondo, $20 \%$ relatou que a percebe quando os funcionários vêm examiná-lo e lhe perguntam se sente dores. Entre estes pacientes, $40 \%$ não soube identificar os momentos em que a hospitalidade é manifestada.

Enquanto analisávamos o contato entre pacientes e funcionários no setor da maternidade, notamos uma ação admirável: após o nascimento das crianças, funcionários parabenizam a nova mamãe pelo seu filho com um cartaz na parede do seu leito. Isso evidencia o $1^{\circ}$ e $8^{\circ}$ parâmetros do Planetree, os quais declaram a importância do contato e interação entre funcionários e pacientes a fim de que os usuários se sintam valorizados.

Intensidade da presença da hospitalidade na unidade de saúde: Taraboulsi (2009, p. 28) ressalta que o paciente precisa de algo além do tratamento médico, que corresponda a um nível de atenção, respeito e uma conversa simples e honesta. Ainda destaca que "[...] essas coisas não vão curar a doença, mas tornam o sofrimento mais tolerável." A presença da hospitalidade surge como uma alternativa para romper o clima de doença, de um ambiente frio e impessoal que predomina nestes ambientes (VERBIST, 2014, p. 123). Além de proporcionarem o tratamento e a cura, os hospitais devem visar o bem-estar dos que buscam pelos seus serviços, contribuindo para a melhoria da situação do paciente em seu estado emocional e, consequentemente, acelerando seu processo de cura.

Figura 01 - Presença da hospitalidade no Hospital Municipal Ruth Cardoso segundo os pacientes.

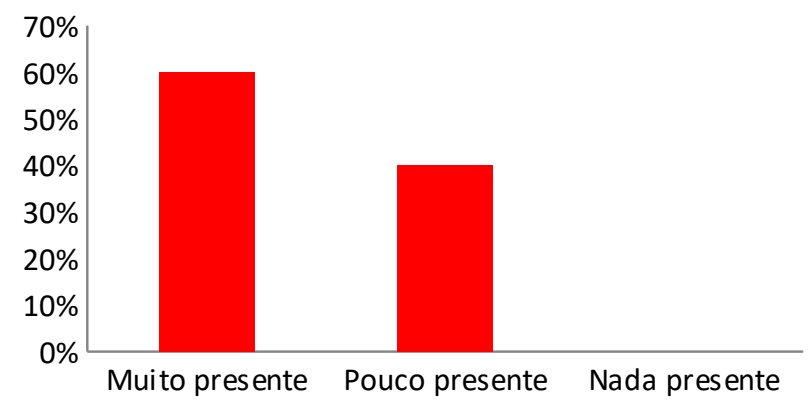

Fonte: dados da pesquisa (2019). 
VIEIRA, M. T. A Importância da Hospitalidade em Unidades de Saúde: um estudo de caso no Hospital Municipal Ruth Cardoso de Balneário Camboriú/SC. Revista Hospitalidade. São Paulo, volume 16, n.02, p. 3-30, 2019. Doi: https://doi.org/10.21714/21799164.2019.v16n2.001.

Conforme a Figura 01 apresenta, entre o total de pacientes entrevistados, a maioria mostra-se satisfeita com a intensidade da manifestação da hospitalidade no Hospital Municipal Ruth Cardoso. $60 \%$ dos pacientes relatou que a hospitalidade é muito presente no local, enquanto os outros $40 \%$ a considera pouco presente. Isto nos indica que o hospital precisa de métodos para corresponder às necessidades de cada paciente de uma forma mais abrangente, a fim de que todos se sintam acolhidos pelos profissionais com as interações humanas e pela infraestrutura do hospital.

Perfil dos profissionais do hospital a partir da perspectiva dos pacientes: Sem comprometimento em desenvolver hábitos hospitaleiros não é possível obter sucesso na execução do trabalho em um local que necessita desta característica. O relacionamento com os pacientes, acompanhantes e colegas de trabalho deve ser cultivado com zelo por cada funcionário, pois uma instituição hospitalar reflete os valores e atitudes daqueles que a compõem.

Figura 02 - Classificação do perfil dos funcionários segundo os pacientes

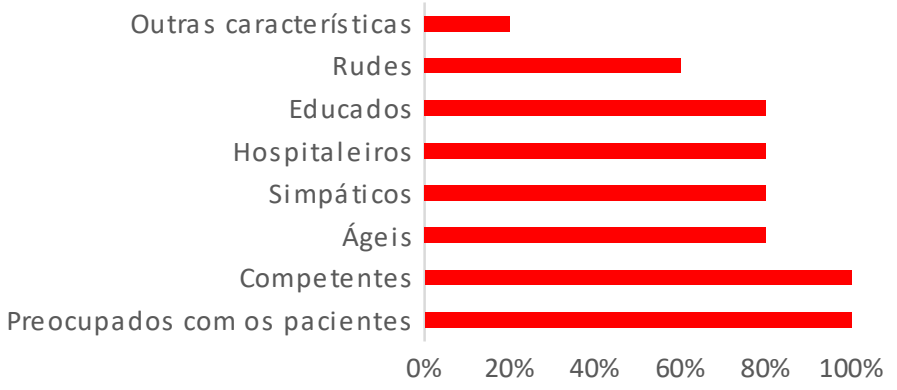

Fonte: dados da pesquisa (2019).

De acordo com as respostas obtidas, percebemos que os profissionais do hospital atendem ao perfil desejado pela maioria dos pacientes, conforme indica a Figura 02. Todos os pacientes entrevistados afirmaram que os profissionais são competentes em seu serviço e que eles demonstram preocupação com os pacientes. Com base nas respostas dos questionários, a característica "rude" concentra-se apenas aos funcionários da recepção, que precisam ser aperfeiçoados no $1^{\mathrm{o}}$ pilar do Planetree, o qual menciona a importância de uma boa interação entre profissionais e usuários. 
Qualidade das refeições: Foi questionado aos pacientes quanto à qualidade das refeições. Indicamos que avaliassem em ótimo, bom, regular, ruim ou péssimo, gerando os seguintes resultados apresentados na Figura 03:

Figura 03- Qualidade das refeições de acordo com os pacientes

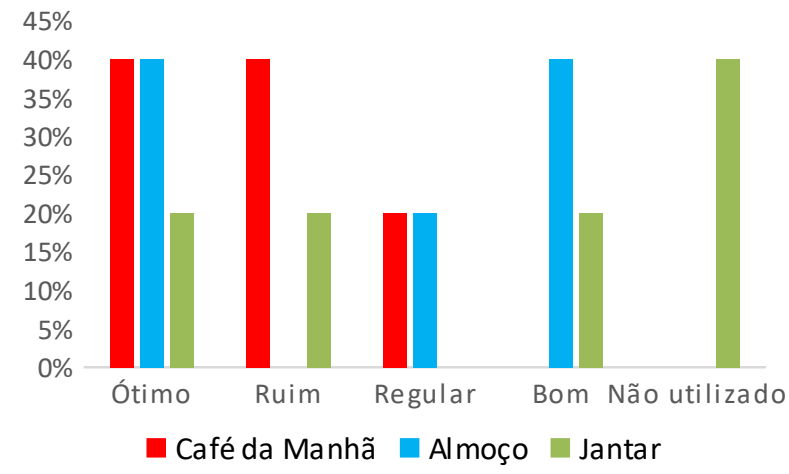

Fonte: dados da pesquisa (2019).

Em relação ao café da manhã/tarde, $40 \%$ dos pacientes considera a refeição ótima, $20 \%$ acha regular e 40\%, ruim. Um paciente propôs a oferta de uma quantidade maior de alimentos, pois, segundo ele, a porção oferecida é insuficiente para quem está em processo de recuperação. Quanto a qualidade do almoço, 40\% dos pacientes avaliou como ótimo, 40\% classificou como bom e $20 \%$, como regular. Quanto ao jantar, 40\% declarou a não utilização deste serviço por estar menos de $24 \mathrm{~h}$ no hospital, $20 \%$ avaliou como ótima, $20 \%$ considerou boa e outros $20 \%$, como ruim.

Os aspectos nutricionais são responsáveis pelo percurso de recuperação. O $5^{\circ}$ componente do Planetree sugere que os centros de saúde disponibilizem cozinhas para que as famílias possam armazenar alimentos para os pacientes ou preparar suas refeições, caso queiram. Porém, os usuários entrevistados responderam que seus acompanhantes são proibidos de levar ou preparar refeições, pois, segundo eles, existe uma orientação nutricional específica para cada tratamento.

Incentivo dado aos familiares e amigos no tratamento: $\mathrm{O}$ suporte às famílias e aos acompanhantes, conforme menciona o $2^{\circ}$ parâmetro do Planetree, garante o envolvimento do ciclo social do paciente na sua cura. Embora as visitas no hospital não sejam permitidas em 
VIEIRA, M. T. A Importância da Hospitalidade em Unidades de Saúde: um estudo de caso no Hospital Municipal Ruth Cardoso de Balneário Camboriú/SC. Revista Hospitalidade. São Paulo, volume 16, n.02, p. 3-30, 2019. Doi: https://doi.org/10.21714/21799164.2019.v16n2.001.

qualquer horário, a liberdade dos visitantes e acompanhantes é notável para alguns dos entrevistados.

Sobre o incentivo aos familiares e amigos no tratamento, a Figura 04 apresenta que $60 \%$ dos pacientes entrevistados informaram que não o identificam. Entretanto, 20\% dos respondentes que notam o incentivo, citaram que a boa explicação do tratamento para a família e a integração que ocorre entre funcionários e familiares é uma manifestação de incentivo.

Figura 04 - Incentivo do hospital para o envolvimento de familiares e amigos na cura do paciente

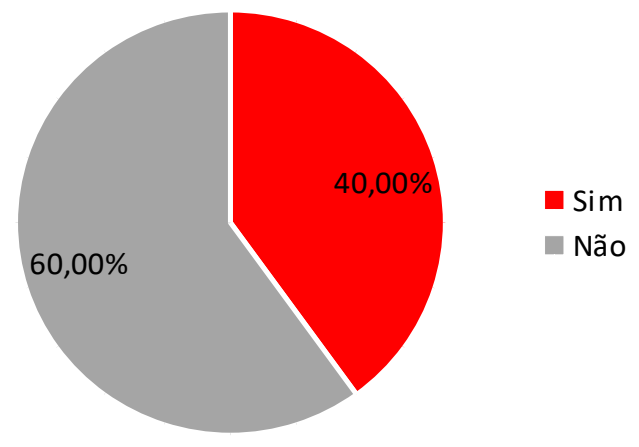

Fonte: dados da pesquisa (2019).

Espera por atendimento: O tempo de espera por atendimento é um dos fatores onde a hospitalidade deve se fazer presente, pois é a primeira impressão que o hospital transmite ao usuário de saúde. Quando questionados sobre o tempo de espera, $80 \%$ dos pacientes constataram que o tempo para a prestação do serviço no hospital é ideal, enquanto os outros $20 \%$ consideram muito demorado.

Conforme analisamos em nossas visitas ao Hospital Municipal Ruth Cardoso, existe uma placa na área de Pronto Atendimento do hospital informando a todos que o atendimento se dá pela classificação de risco, e não pela ordem de chegada, o que justifica a demora do atendimento a casos menos graves.

Entretenimento oferecido aos pacientes: Conforme o $6^{\circ}$ pilar do Planetree, o entretenimento torna o ambiente hospitalar mais acolhedor. Dentre os entretenimentos sugeridos pela filosofia, o hospital estudado oferece apenas apresentações musicais uma vez por semana, 
VIEIRA, M. T. A Importância da Hospitalidade em Unidades de Saúde: um estudo de caso no Hospital Municipal Ruth Cardoso de Balneário Camboriú/SC. Revista Hospitalidade. São Paulo, volume 16, n.02, p. 3-30, 2019. Doi: https://doi.org/10.21714/21799164.2019.v16n2.001.

porém $80 \%$ dos pacientes entrevistados afirmou não ter conhecimento destas apresentações conforme demonstrado na Figura 05. Além de promover maior divulgação das apresentações musicais, sugere-se que o hospital ofereça mais opções de lazer e entretenimento aos seus usuários além da música e dos palhaços, pois isto cria uma atmosfera mais agradável, tranquila e divertida.

Figura 05 - Entretenimento oferecido pelo Hospital Municipal Ruth Cardoso

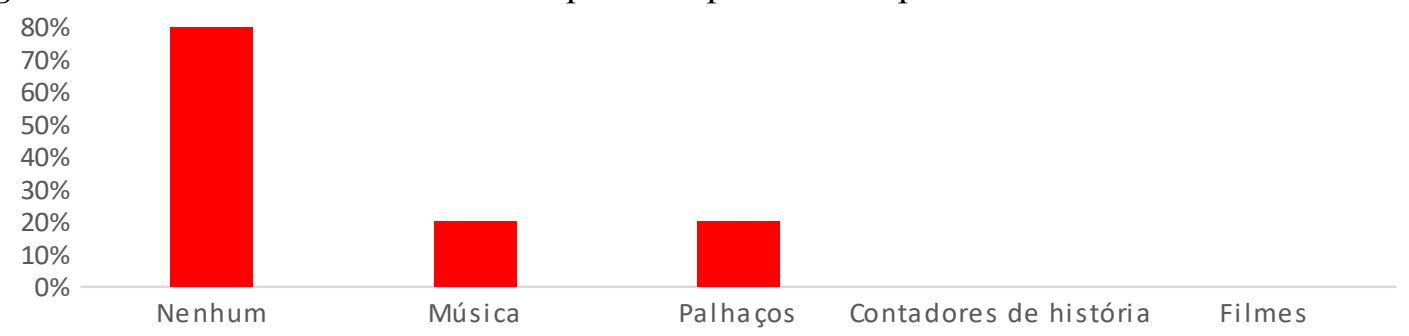

Fonte: dados da pesquisa (2019).

Sugestão para a melhoria da hospitalidade no Hospital Municipal Ruth Cardoso: Os pacientes tiveram a oportunidade de sugerir melhorias na hospitalidade. Dentre os entrevistados, $20 \%$ mencionou que os funcionários poderiam ser mais hospitaleiros na chegada do paciente no hospital, realizando um atendimento mais rápido e prestativo. Também, 20\%, sugeriu que os recepcionistas fossem mais cordiais, pois, segundo ele, são "grossos", diferente dos demais profissionais do hospital, que são educados e preocupados com os pacientes. Os pacientes ressaltaram, de forma geral, o descontentamento com os serviços prestados pelos recepcionistas. A recepção é, muitas vezes, o primeiro contato do usuário com a unidade de saúde. Por isso, é fundamental a garantia da qualidade no serviço através da paciência, educação e agilidade ao atender as necessidades dos usuários. Conforme o $1^{\circ}$ parâmetro do Planetree, a preocupação com o outro cria um ambiente de cura para os pacientes e demais envolvidos.

\section{Acompanhantes}

Para a obtenção das informações apresentadas a seguir, foram aplicados 5 questionários para 5 acompanhantes, que, para fins de análise, representarão $100 \%$ da amostra. Estes acompanhantes foram eleitos pela coordenadora de hotelaria hospitalar, que nos acompanhou em 
VIEIRA, M. T. A Importância da Hospitalidade em Unidades de Saúde: um estudo de caso no Hospital Municipal Ruth Cardoso de Balneário Camboriú/SC. Revista Hospitalidade. São Paulo, volume 16, n.02, p. 3-30, 2019. Doi: https://doi.org/10.21714/21799164.2019.v16n2.001.

toda a etapa da coleta de dados. O questionário foi constituído por 14 questões e revelou informações nos seguintes indicadores:

Presença da hospitalidade no Hospital Municipal Ruth Cardoso: Por tratar-se de um aspecto tão importante, atualmente a hospitalidade é considerada um requisito básico. Sendo assim é cobrada pelos usuários de saúde (pacientes, acompanhantes e visitantes) não como um diferencial, mas sim como uma exigência. Taraboulsi (2009, p. 3) assim destaca que:

Atualmente, os clientes de saúde sabem que a tecnologia e o conhecimento técnico e científico estão ao alcance de todas as instituições de saúde, entretanto, eles procuram e exigem atendimento hospitalar humanizado: respeito, carinho, dedicação e serviços de hotelaria em que o sorriso se faz presente de uma forma sincera e permanente.

No Hospital Municipal Ruth Cardoso, 80\% dos acompanhantes disse perceber a hospitalidade como fator muito presente, enquanto os $20 \%$ restantes respondeu que a hospitalidade é pouco presente no ambiente como demonstra a Figura 06. Com isto, podemos dizer que, na visão da maioria dos acompanhantes entrevistados nesta pesquisa, o Hospital Municipal Ruth Cardoso é um local hospitaleiro.

Figura 06 - Presença da hospitalidade no Hospital Municipal Ruth Cardoso segundo os acompanhantes

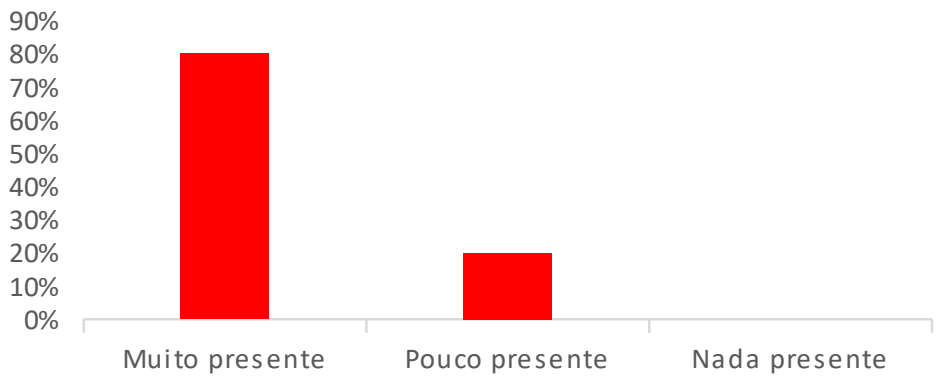

Fonte: dados da pesquisa (2019).

Quando questionados sobre momentos em que a hospitalidade se faz presente, $20 \%$ dos acompanhantes entrevistados que disse perceber a presença da hospitalidade no Ruth Cardoso não soube informar em quais momentos a mesma se faz presente. $20 \%$ dos acompanhantes identifica a hospitalidade no oferecimento de um tratamento mais humanizado. $20 \%$ ainda cita a preocupação constante dos funcionários, tanto com a limpeza dos ambientes hospitalares quanto em atender às necessidades dos usuários do hospital. 20\% dos acompanhantes menciona a boa disposição dos enfermeiros na realização do parto e $20 \%$ dos acompanhantes entrevistados cita 
VIEIRA, M. T. A Importância da Hospitalidade em Unidades de Saúde: um estudo de caso no Hospital Municipal Ruth Cardoso de Balneário Camboriú/SC. Revista Hospitalidade. São Paulo, volume 16, n.02, p. 3-30, 2019. Doi: https://doi.org/10.21714/21799164.2019.v16n2.001.

o bom atendimento como o momento onde a hospitalidade se fez presente. Com estas respostas, podemos afirmar que o hospital em questão atende ao primeiro pilar do Planetree, pois demonstra preocupação com o bem-estar de seus usuários.

Perfil dos profissionais do hospital a partir da perspectiva dos acompanhantes: A hospitalidade integra a equipe com o objetivo de diferenciar os serviços prestados, atender bem e encantar o cliente. A hospitalidade oferecida pelo hospital tem em sua missão "um conjunto de valores, modelos e ações que dizem respeito ao receber humano". (CAMARGO, 2004, apud RIBEIRO, 2013, p.30).

Sobre a equipe de funcionários do hospital, 100\% dos acompanhantes entrevistados afirmaram que os profissionais são ágeis, simpáticos, hospitaleiros, preocupados com os pacientes, educados e competentes conforme apresenta a Figura 07. Destes acompanhantes, apenas 20\% acrescentou que alguns funcionários da unidade de saúde são rudes e outro acompanhante entrevistado ainda mencionou que colaboradores do hospital são atenciosos.

Figura 07 - Classificação do perfil dos funcionários segundo os acompanhantes

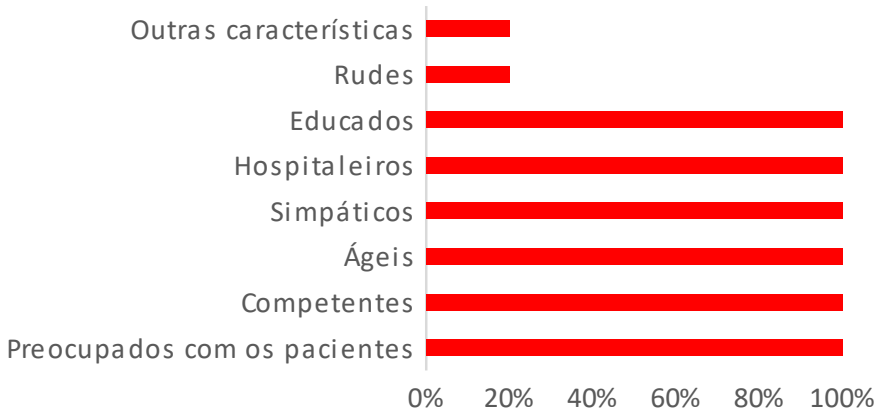

Fonte: dados da pesquisa (2019).

Qualidade das refeições: $O 5^{\circ}$ pilar do Planetree sugere que os centros de saúde disponibilizem, em sua estrutura, cozinhas para que as famílias possam trazer de casa os alimentos favoritos dos pacientes ou até mesmo para que preparem as refeições eles mesmos, caso queiram, porém $80 \%$ dos acompanhantes entrevistados respondeu que não possui liberdade para levar para ao hospital estudado os alimentos preferidos do paciente. Dentre esses acompanhantes, dois ressaltaram que a medida é eficiente, pois evita que o paciente coma algo fora de sua dieta. Por fim, 100\% dos acompanhantes entrevistados declararam que não há um 
VIEIRA, M. T. A Importância da Hospitalidade em Unidades de Saúde: um estudo de caso no Hospital Municipal Ruth Cardoso de Balneário Camboriú/SC. Revista Hospitalidade. São Paulo, volume 16, n.02, p. 3-30, 2019. Doi: https://doi.org/10.21714/21799164.2019.v16n2.001.

espaço disponível no hospital para que os acompanhantes possam preparar as comidas para o paciente.

No questionário, ainda, pedimos para que os acompanhantes avaliassem a qualidade das refeições em ótimo, bom, regular, ruim ou péssimo, gerando os resultados apresentados na Figura 08:

Figura 08 - Avaliação das refeições pelos acompanhantes

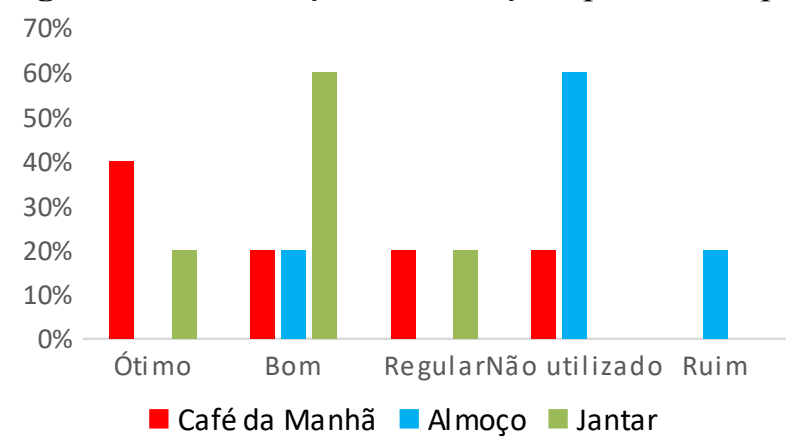

Fonte: dados da pesquisa (2019).

Quanto ao café da manhã, 40\% dos acompanhantes entrevistados avaliou como ótimo, $20 \%$ como bom, $20 \%$ como regular e $20 \%$ declararam não terem usufruído deste serviço. Um dos acompanhantes sugeriu que, além do café e do pão, fosse oferecida alguma fruta no café da manhã. Em relação ao almoço, $60 \%$ dos acompanhantes entrevistados na pesquisa disse não ter utilizado o serviço, enquanto $20 \%$ dos acompanhantes avaliou o almoço como bom. Os $20 \%$ restantes considera a qualidade do almoço regular. Foi sugerido por parte de um dos acompanhantes que o arroz e o feijão fossem servidos separadamente nesta refeição. Quando perguntamos sobre a qualidade do jantar, $60 \%$ dos acompanhantes considera o serviço bom, $20 \%$ dos entrevistados qualifica o jantar como ótimo e $20 \%$ como regular. Um dos acompanhantes entrevistados sugeriu que houvesse uma maior variedade de alimentos, pois, segundo ele, o hospital só oferece sopa nessa refeição.

Incentivo dos familiares e amigos no tratamento: Conforme o segundo pilar do Planetree, o apoio de familiares e amigos é fundamental para a recuperação do paciente. Neste pilar, propõe-se que sejam oferecidos horários livres de visitas e que familiares sejam incentivados a passar a noite no hospital junto ao paciente. $40 \%$ dos acompanhantes respondeu 
VIEIRA, M. T. A Importância da Hospitalidade em Unidades de Saúde: um estudo de caso no Hospital Municipal Ruth Cardoso de Balneário Camboriú/SC. Revista Hospitalidade. São Paulo, volume 16, n.02, p. 3-30, 2019. Doi: https://doi.org/10.21714/21799164.2019.v16n2.001.

que a visita ao paciente necessita de agendamento prévio, outros $40 \%$ disse que familiares e amigos possuem liberdade para visitar o paciente a qualquer momento. Os $20 \%$ restantes não souberam responder a esta pergunta. Tivemos uma conversa com a coordenadora de hotelaria do hospital, a qual nos esclareceu que a visita possui horários pré-estabelecidos pelo hospital. Quando perguntado sobre o incentivo de familiares e amigos no tratamento, $60 \%$ dos acompanhantes nos informou que este incentivo não é oferecido. $20 \%$ dos acompanhantes disse que o incentivo é oferecido, mas não soube informar de que forma. $20 \%$ dos acompanhantes citou que o incentivo de familiares e amigos é oferecido, pois a visita é realizada em um bom ambiente e a troca de acompanhantes também é incentivada.

Espera por atendimento: Quando questionados sobre o tempo de espera por atendimento, $80 \%$ dos acompanhantes entrevistados disse que consideram este tempo ideal no hospital. Destes acompanhantes, um nos informou que, na verdade, a espera por atendimento depende da situação e que em outras vezes em que precisou de atendimento médico chegou a ficar esperando mais de duas horas para ser atendido. Os $20 \%$ restantes declarou que o tempo de espera é demorado.

\section{Sugestão para melhoria da hospitalidade no Hospital Municipal Ruth Cardoso:} Perguntamos aos acompanhantes se estes teriam alguma sugestão de melhoria para que haja maior hospitalidade no Hospital Municipal Ruth Cardoso e obtivemos as seguintes respostas e $60 \%$ destes entrevistados citou a que as poltronas poderiam ser melhores e reclináveis, demonstrando insatisfação com a falta de conforto dentro dos quartos do hospital. Como os acompanhantes dormem em poltronas, eles sugerem que estas sejam reclináveis ou que haja disponibilidade de um sofá, o que indica a importância do conforto do acompanhante para a disposição do mesmo em zelar pelo paciente. $20 \%$ dos acompanhantes sugere que mais médicos sejam contratados, pois assim o atendimento seria mais ágil. Por fim, 20\% disse não ter nenhuma sugestão de melhoria, demonstrando satisfação total em relação aos serviços oferecidos pelo hospital.

Podemos concluir com estes resultados que o Hospital Municipal Ruth Cardoso deveria se preocupar em oferecer maior conforto aos seus acompanhantes. O conforto contribui para a formação de um ambiente acolhedor e hospitaleiro e deve ser oferecido não apenas aos pacientes, mas também aos seus acompanhantes. 
VIEIRA, M. T. A Importância da Hospitalidade em Unidades de Saúde: um estudo de caso no Hospital Municipal Ruth Cardoso de Balneário Camboriú/SC. Revista Hospitalidade. São Paulo, volume 16, n.02, p. 3-30, 2019. Doi: https://doi.org/10.21714/21799164.2019.v16n2.001.

\section{Colaboradores e diretor-geral}

Aplicamos o instrumento de pesquisa com o diretor-geral e cinco coordenadores do Hospital Municipal Ruth Cardoso. Os questionários apresentaram perguntas comuns a todos e outras específicas de acordo com as peculiaridades de cada setor.

Entendimento da hospitalidade: Para a coordenadora de atendimento, a hospitalidade consiste em receber e cuidar de alguém para que esta pessoa se sinta acolhida. Já a coordenadora de hotelaria hospitalar destaca que a hospitalidade é um termo individual e que sua construção depende de um grupo de pessoas. A mesma cita como exemplos o sorriso no rosto e o ato de chamar o paciente pelo nome, demonstrando respeito e atenção. Camas bem forradas e lençóis bem passados e limpos são sinais de cordialidade, segundo ela. Sua resposta evidencia a manifestação da hospitalidade através dos detalhes, pois por mais simples que pareçam ser, fazem a diferença durante o tratamento. O coordenador de enfermagem diz que a hospitalidade é acolher da melhor forma possível, enquanto a coordenadora de nutrição declara que hospitalidade é se colocar no lugar do próximo e atender de forma humana. O coordenador em segurança do trabalho caracteriza a hospitalidade como o melhor atendimento prestado, à medida que o diretor do hospital menciona o ato de receber e acolher com humanização cada paciente e familiar que os procura.

Intensidade e momentos de manifestação da hospitalidade: Ao serem questionados quanto a intensidade em que a hospitalidade é demonstrada, $80 \%$ dos colaboradores afirma que ela está muito presente na unidade de saúde, enquanto $20 \%$, contrapondo, afirma que está pouco presente.

Quanto aos momentos em que a hospitalidade se manifesta com evidência, a coordenadora de atendimento menciona as situações de notícia de óbito, onde o médico junto aos serviços de assistência social e psicologia comunicam os familiares.

A coordenadora de hotelaria identifica a hospitalidade quando o paciente é atendido pelo médico sendo chamado pelo seu nome, e, quando a funcionária da higienização dos leitos ao entrar no quarto do paciente lhe cumprimenta, dando bom dia/tarde/noite. Já a coordenadora de enfermagem respondeu precisamente que percebe a hospitalidade durante a triagem e na recepção. 
VIEIRA, M. T. A Importância da Hospitalidade em Unidades de Saúde: um estudo de caso no Hospital Municipal Ruth Cardoso de Balneário Camboriú/SC. Revista Hospitalidade. São Paulo, volume 16, n.02, p. 3-30, 2019. Doi: https://doi.org/10.21714/21799164.2019.v16n2.001.

A coordenadora de nutrição declara que a hospitalidade é expressa através da abordagem de forma simpática e respeitosa às famílias, na disponibilidade de um serviço de psicologia e na assistência social oferecida aos usuários. Também menciona as portas abertas à sociedade para reclamações, sugestões e elogios quanto aos serviços prestados. Enquanto o técnico em segurança do trabalho evidencia que a hospitalidade se faz presente na atenção dada ao internado e à sua família por meio do setor de psicologia, fisioterapia, fonoaudiologia, nutrição, e, quando necessário, assistência social.

Motivação recebida para a realização de sua função: Cada colaborador deu respostas diferentes a respeito das motivações recebidas no hospital. Porém podemos notar que apesar de encontrarem o estímulo de diferentes formas, todos são incentivados à realização do seu trabalho.

O diretor do hospital afirma que cada coordenador das equipes fica responsável por repassar os elogios recebidos, e isso é uma forma de motivação e reconhecimento pelo trabalho de cada um. Já a coordenadora de atendimento caracteriza como um incentivo o treinamento oferecido a toda equipe administrativa e a conversa diária com a equipe para que possam fazer melhor que ontem. Ela ainda destacou que "estamos em constante reforma de aprendizado e conhecimento".

Ademais a coordenadora de hotelaria relatou que é motivada pela liberdade para trabalhar e tratar de assuntos pertinentes da sua área, como por exemplo o treinamento das equipes com o objetivo de ter resultados positivos, tanto para a área de atendimento quanto na área de higienização. O coordenador de enfermagem é incentivado pela orientação, capacitação e palestras. Enquanto a coordenadora de nutrição é motivada quanto há melhoria no quadro clínico de um paciente, resultante do seu esforço profissional. Também citou o reconhecimento por parte da direção e colegas de quando se esforça para fazer a diferença. Já o técnico em segurança do trabalho mencionou que é encorajado para a realização de seu trabalho pela "constante prevenção de doenças relacionadas ao trabalho dos funcionários do Ruth Cardoso", demonstrando que se preocupa com o bem-estar de seus colegas de trabalho.

\section{Reconhecimento e valorização do serviço prestado pelos demais setores e}

funcionários do hospital: A coordenadora de atendimento relatou que às vezes se sente valorizada e que todos os setores precisam estar sintonizados para tudo fluir de acordo com que esperam, "ainda temos dificuldade na sincronia" destaca. A coordenadora de hotelaria ressalta 
VIEIRA, M. T. A Importância da Hospitalidade em Unidades de Saúde: um estudo de caso no Hospital Municipal Ruth Cardoso de Balneário Camboriú/SC. Revista Hospitalidade. São Paulo, volume 16, n.02, p. 3-30, 2019. Doi: https://doi.org/10.21714/21799164.2019.v16n2.001.

que seu trabalho é reconhecido quando os outros coordenadores e demais funcionários do hospital a elogiam, e ela retribui passando essa motivação à sua equipe. O coordenador de enfermagem nota a valorização quando os funcionários são parabenizados e agradecidos. A coordenadora de nutrição destaca que se sente valorizada quando há respeito quanto as decisões pertinentes ao seu setor e sempre que recebe elogios pelo seu serviço prestado. O técnico em segurança do trabalho afirma que "há um reconhecimento, pois as políticas de prevenção de acidentes adotadas reduziram as ocorrências. Além das fiscalizações feitas diariamente, que reduziram alguns 'incômodos' como por exemplo, o cheiro de cigarro, pois não se fuma mais em torno do hospital", tornando evidente que o respeito pelas medidas adotadas pelo seu trabalho é uma forma de valorizar o mesmo.

Acompanhamento psicológico oferecido aos pacientes e acompanhantes e aos funcionários do hospital: O diretor do assegura que no Hospital Municipal Ruth Cardoso há uma equipe multidisciplinar composta por psicólogos e assistente social que presta suporte aos que precisam e buscam pelos serviços da unidade de saúde. Essa assistência se dá tanto à comunidade local, quanto aos próprios funcionários do hospital.

Espaços disponíveis para lazer dos colaboradores no hospital: O diretor do hospital afirma que os funcionários podem usufruir de todos os espaços (sala de estar, sala de atividades e cozinha) e que possuem liberdade para assistirem as apresentações teatrais que ocorrem todas as quartas-feiras no período da noite para os usuários do hospital.

As coordenadoras de: atendimento, hotelaria e enfermagem, alegaram que não existem espaços apropriados para o lazer dos colaboradores no hospital.

Contrapondo, a coordenadora de nutrição mencionou que aproveita para descansar durante os intervalos para café e almoço. Ainda destaca que, se a leitura ou o estudo forem pertinentes a algo a se aplicar em seu trabalho no hospital, tem todo o seu turno para realizá-los. O técnico em segurança do trabalho mencionou que no hospital há sofás e cadeiras para descanso, e que, para os funcionários do período noturno, são disponibilizados quartos de descanso, pois a jornada de trabalho à noite é de 12 horas.

A arquitetura e design ( $4^{\circ}$ componente do Planetree) do hospital estudado não corresponde às necessidades de todos os colaboradores. Em nossas observações nas áreas hospitalares, percebemos que outras áreas poderiam ser disponibilizadas além da sala de TV e 
VIEIRA, M. T. A Importância da Hospitalidade em Unidades de Saúde: um estudo de caso no Hospital Municipal Ruth Cardoso de Balneário Camboriú/SC. Revista Hospitalidade. São Paulo, volume 16, n.02, p. 3-30, 2019. Doi: https://doi.org/10.21714/21799164.2019.v16n2.001.

postos dos setores (onde os profissionais de cada setor se reúne para tratar de assuntos referentes aos pacientes), a fim de que os profissionais se sintam mais acolhidos pelo seu local de trabalho, tendo mais prazer no mesmo.

\section{Reconhecimento dos pacientes e acompanhantes ao tratamento hospitaleiro} prestado pelos colaboradores: A coordenadora de atendimento mencionou que muitas vezes os profissionais do hospital recebem mensagens por escrito ou presentes pela forma como foram recebidos e acolhidos, destacando que muitos usuários demonstram gratidão pelos serviços prestados.

A coordenadora de hotelaria afirma que constantemente passa nos quartos dos pacientes para perguntá-los se estão bem, se a limpeza está sendo realizada e se precisam de alguma ajuda e ressalta que essa atitude faz uma grande diferença, pois os usuários do hospital sentem-se valorizados e a retornam com um sorriso de agradecimento.

O coordenador de enfermagem sente que seu trabalho é reconhecido através de agradecimentos, presentes e elogios. Enquanto a coordenadora de nutrição percebe essa valorização através de palavras de gratidão de familiares ou do próprio paciente, seja pessoalmente, através de cartas ou postagem em redes sociais.

Quando um bom serviço é oferecido, bons resultados são obtidos. As interações humanas ( $1^{\circ}$ pilar do Planetree) se fortalecem ainda mais quando há um esforço mútuo. Podemos perceber que os colaboradores são ainda mais incentivados a continuarem prestando um serviço de qualidade quando há reconhecimento por parte dos pacientes e familiares do mesmo.

Efeitos percebidos com a presença da hospitalidade no tratamento aos pacientes: A coordenadora de atendimento afirma que, em momentos difíceis, pacientes e familiares precisam de alguém que os ouça e os dê um abraço ou um sorriso para amenizar a dor vivenciada. Segundo a coordenadora de hotelaria, a hospitalidade faz o paciente se sentir valorizado, e, como efeito, sua estadia no hospital tende a diminuir. A presença da hospitalidade é nitidamente percebida na melhora dia após dia e na rapidez da alta hospitalar, como afirma o diretor. As respostas obtidas demonstram que o hospital está de acordo com o $8^{\circ}$ pilar do Planetree, o qual menciona que o toque humano e a atenção às necessidades dos pacientes contribuem positivamente para a sua cura. 
VIEIRA, M. T. A Importância da Hospitalidade em Unidades de Saúde: um estudo de caso no Hospital Municipal Ruth Cardoso de Balneário Camboriú/SC. Revista Hospitalidade. São Paulo, volume 16, n.02, p. 3-30, 2019. Doi: https://doi.org/10.21714/2179$\underline{9164.2019 . v 16 n 2.001 .}$.

Incentivo à ampliação de conhecimentos aos funcionários em suas áreas de atuação a partir de cursos de qualificação/capacitação: O diretor do Hospital Municipal Ruth Cardoso certifica que todos os funcionários do hospital participam de cursos específicos de acordo com a área de sua formação e que o hospital possui um setor de educação e capacitação contínua.

Preparação do cardápio alimentar do Hospital Municipal Ruth Cardoso: No hospital estudado a base de cardápio é a mesma para todos, porém, a coordenadora de nutrição justificou que cada preparação é adaptada segundo a necessidade específica, por exemplo: "se tenho batata na dieta livre, terei purê de batata na dieta pastosa e batata-doce ou outro legume na dieta para pacientes com diabetes". Ao contrário do que estabelece o $5^{\circ}$ parâmetro do Planetree, os acompanhantes e visitantes não possuem liberdade para cozinhar os alimentos preferidos do paciente no hospital.

Arquitetura inclusiva e acessível à deficientes físicos: $\mathrm{O}$ coordenador em segurança no trabalho reconhece que alguns rebaixos das calçadas precisam ser refeitos, pois há saliências que dificultam o acesso das cadeiras de rodas. Em contraponto, ressalta que o hospital foi edificado na horizontal, facilitando a locomoção entre setores. O coordenador garante que os acessos são facilitados aos cadeirantes com rebaixos de meio-fio, portas largas e banheiros adequados. Entretanto, em nossas observações, encontramos uma realidade diferente: O hospital dispõe rampas de acesso apenas no pronto socorro e no ambulatório, mas as calçadas das demais áreas não são adaptadas aos cadeirantes e os banheiros não possuem barras de apoio. O artigo $9 \S 3^{\circ}$ da portaria $\mathrm{n}^{\mathrm{o}} 3.390$, de 30 de dezembro de 2013, declara que "a ambiência hospitalar deverá adotar uma arquitetura inclusiva e com acessibilidade, seguindo as normas e legislações vigentes". O responsável pela infraestrutura do hospital assume que alguns itens precisam ser melhorados, como espaços adaptados aos deficientes visuais, incluindo informações em braile, piso tátil de alerta e direcional.

Espera por atendimento: A coordenadora de atendimento e o diretor admitem que a espera por atendimento é demorada, mas justificam dizendo que se deve levar em conta a grande demanda de emergência atendida pelo hospital. Em nossas visitas à instituição foi possível observar que na área de pronto atendimento há uma placa informando que o atendimento se dá pela classificação de risco e não pela ordem de chegada. De acordo com o diretor, existe a triagem prévia dos pacientes e o tempo de espera é classificado de acordo com o tipo de diagnóstico. 
VIEIRA, M. T. A Importância da Hospitalidade em Unidades de Saúde: um estudo de caso no Hospital Municipal Ruth Cardoso de Balneário Camboriú/SC. Revista Hospitalidade. São Paulo, volume 16, n.02, p. 3-30, 2019. Doi: https://doi.org/10.21714/21799164.2019.v16n2.001.

Visitas de familiares e amigos: $O$ diretor e a coordenadora de atendimento nos informaram que as visitas de familiares e amigos necessitam de agendamento prévio. "A cada horário de visitas em clínicas são autorizadas 4 visitantes por paciente, na UTI são 3 horários sendo autorizados, 2 visitas a cada horário. UTI neonatal é livre. Pediatria além do acompanhante segue as regras dos horários das clínicas", afirma a coordenadora de atendimento. A mesma colaboradora ainda nos informa que o atendimento no hospital é realizado de acordo com o nível de complexidade, e não conforme a ordem de chegada. Os horários estão no Anexo 02.

Animais de estimação: Conforme o segundo pilar do Planetree, a terapia com animais de estimação pode melhorar o humor, elevar os níveis de pressão arterial e a interação social. Por isso, é muito importante para a recuperação do paciente que o hospital aceite animais de estimação. O diretor e o coordenador de enfermagem afirmaram que no Hospital Municipal Ruth Cardoso são aceitos animais de estimação. O diretor nos relatou que, semanalmente, o hospital recebe a visita de cães treinados para estarem no local e visitarem os pacientes. Disse, ainda, que isso ajuda muito a autoestima dos pacientes e que em muitos dos casos é a única visita que aquele paciente terá no dia.

Incentivo de familiares/amigos no tratamento: Segundo o diretor do hospital, este incentivo é oferecido através de orientações: "são orientados a dar sequência nos tratamentos e acompanhamentos em sua residência. O profissional da enfermagem fica responsável em repassar essas orientações", diz o diretor. O coordenador de enfermagem reforçou a resposta do diretor, nos dizendo, também, que são realizadas orientações dos cuidados ao paciente. Ainda, o mesmo colaborador nos informou que pacientes do Hospital Municipal Ruth Cardoso não possuem direito a acompanhante 24 horas por dia. Somente idosos e menores de idade.

Espiritualidade: O sétimo pilar do Planetree dispõem sobre o papel da espiritualidade no tratamento e na cura do paciente e ressalta a importância de locais para orações e reflexões, como capelas e salas de meditação. O diretor, ao responder o questionário, nos comunicou sobre a indisponibilidade de locais como estes no hospital.

Medidas sustentáveis adotadas pelo hospital: "Ao trabalhar com escolas, centros de terceira idade, igrejas e outros parceiros na comunidade, os hospitais estão redefinindo a saúde para incluir a saúde e o bem-estar da comunidade como um todo. Ao escolher produtos de limpeza que não poluem o ambiente, grupos de caminhada e jardins comunitários, expande-se o 
VIEIRA, M. T. A Importância da Hospitalidade em Unidades de Saúde: um estudo de caso no Hospital Municipal Ruth Cardoso de Balneário Camboriú/SC. Revista Hospitalidade. São Paulo, volume 16, n.02, p. 3-30, 2019. Doi: https://doi.org/10.21714/21799164.2019.v16n2.001.

papel dos hospitais, passando do tratamento exclusivo de doenças para a promoção do bemestar". Isto é o que orienta o décimo pilar do planetree, tendo em vista a sustentabilidade em todos os seus âmbitos. Segundo o diretor, apenas uma destas seis medidas é adotada pelo hospital: a escolha por produtos de limpeza que não poluam o ambiente.

Contribuição do alimento e sua apresentação tratamento do paciente: O quinto pilar do Planetree afirma que a nutrição é essencial ao processo de cura, pois, além da boa saúde, também é vista como fonte de prazer, conforto e familiaridade. Segundo a coordenadora de nutrição do hospital, o alimento é tão importante quanto a medicação. "é ele que vai nutrir o paciente durante um tratamento com antibióticos, no pós-operatório de uma cirurgia, na cicatrização de uma lesão por pressão, durante um tratamento de quimioterapia, enfim, em todos os casos de estresse metabólico; e a apresentação de forma atraente e harmoniosa aumenta significativamente a aceitação dele, destaca a colaboradora.

Relacionamento dos funcionários e usuários do hospital: A coordenadora de atendimento e o coordenador de enfermagem do hospital dizem que consideram humanizado o relacionamento dos funcionários do setor em que atuam com os pacientes e acompanhantes. Segundo a coordenadora de atendimento, os funcionários do setor tentam passar toda atenção que cada usuário precisa. O coordenador de enfermagem afirma que está humanização se dá pela educação e respeito às crenças do paciente.

Sugestões de melhoria: A coordenadora de atendimento sugere que haja identificação de usuários, humanização do corpo clínico e sincronia entre os demais setores. Na opinião da coordenadora de hotelaria, a triagem no atendimento ao paciente deve ser aperfeiçoada, pois, nela o usuário perceberá o que lhe espera adiante. Ainda segundo a coordenadora, já estão sendo oferecidos treinamentos sobre hospitalidade na atual gestão. Para a coordenadora de nutrição, deveria haver capacitação constante a todos que tem contato direto com os usuários.

Em nossa perspectiva, alguns itens correspondentes à infraestrutura do hospital necessitam ser melhorados, a começar pela acessibilidade. Verificamos, por exemplo, que o estacionamento não está devidamente sinalizado. Os corredores não possuem janelas e a iluminação artificial se dá por meio de lâmpadas amarelas. Desta forma, evidenciamos que o $4^{\circ}$ pilar do Planetree (Arquitetura e design - ambiente de cura) é pouco garantido pelo hospital, o qual poderia oferecer uma infraestrutura mais aconchegante e inclusiva. 
VIEIRA, M. T. A Importância da Hospitalidade em Unidades de Saúde: um estudo de caso no Hospital Municipal Ruth Cardoso de Balneário Camboriú/SC. Revista Hospitalidade. São Paulo, volume 16, n.02, p. 3-30, 2019. Doi: https://doi.org/10.21714/21799164.2019.v16n2.001.

\section{Conclusões}

Ao final deste estudo de caso podemos afirmar que Hospital Municipal Ruth Cardoso, apesar de suas limitações na infraestrutura e em alguns setores, consegue corresponder ao nível de hospitalidade requerido pela maioria de seus usuários. A instituição de saúde não abrange todos os aspectos hospitaleiros, no entanto, os profissionais, junto ao diretor, apresentaram interesse em melhorar o atendimento prestado e do relacionamento com o grande número de pacientes e acompanhantes que utilizam os serviços do hospital. Na recepção da instituição são disponibilizados questionários para que os usuários avaliem o grau de satisfação em relação ao atendimento, o que evidencia preocupação com a opinião do público.

Ao confrontarmos com a filosofia Planetree percebemos que a unidade de saúde apresenta algumas falhas e não atende plenamente aos dez parâmetros estabelecidos, o que indica um desafio para seus gestores e colaboradores na constante melhoria de seus serviços e infraestrutura buscando a humanização no atendimento como uma missão da instituição.

Os objetivos propostos para realização da pesquisa foram cumpridos: identificamos o entendimento que os colaboradores e usuários do hospital possuem quanto à hospitalidade, verificamos em quais setores os usuários do hospital mais carecem do tratamento humanizado e, como proposta de conscientização, elaboramos um documento de acordo com os dez parâmetros da filosofia Planetree para auxiliar os gestores do Hospital Municipal Ruth Cardoso a desenvolverem práticas mais humanizadas na relação entre pacientes e acompanhantes que usufruem do serviço da unidade de saúde. O Planetree sugere uma estrutura diferenciada e completa para hospitais, que não é a realidade do hospital estudado. Porém, a filosofia também possui parâmetros quanto às relações humanas que podem ser devidamente cumpridos pelo Hospital Municipal Ruth Cardoso se houver dedicação de toda a equipe.

Para tanto, levando em consideração o fato de que os hospitais são um sistema complexo, onde um setor e as pessoas que dele fazem parte exercem influência sobre os demais, deverão ser pensados e estruturados no sentido de oferecer um diferencial em relação aos demais. Esse diferencial, que pode ser a hospitalidade, conforme foi apresentado no decorrer deste estudo, não 
VIEIRA, M. T. A Importância da Hospitalidade em Unidades de Saúde: um estudo de caso no Hospital Municipal Ruth Cardoso de Balneário Camboriú/SC. Revista Hospitalidade. São Paulo, volume 16, n.02, p. 3-30, 2019. Doi: https://doi.org/10.21714/21799164.2019.v16n2.001.

é só mais um diferencial, mas uma exigência para as instituições de saúde, que precisam considerar não só a técnica, mas também o lado humano da internação.

A Hospitalidade e a Humanização são ferramentas para a transformação social. A relação entre os órgãos públicos, o Estado representado nesse caso pela Secretaria de Saúde do município e o que a população demanda é uma provável direção apontada para a continuidade em investigações futuras. A questão política é muito presente quando o assunto em pauta é saúde, algo que não foi levantado por não ser objetivo deste estudo, embora reconheçamos sua relevância.

\section{Referências}

BAPTISTA, Leandro; ROSSETTO, Edgar. Estudo do serviço de hotelaria hospitalar no âmbito público: caso de Ponta Grossa-PR. TURyDES, v. 9, n. 20, 2016.

BOEGER, Marcelo Assad. Gestão em hotelaria hospitalar. São Paulo: Atlas, 2003.

CAMARGO, L. O. L. Hospitalidade. São Paulo: Aleph, 2004.

CHIZZOTTI, A. Pesquisa em ciências humanas e sociais. 2. ed. São Paulo: Cortez, 1995.

FROZÉ. Valéria Dellamano. A hospitalidade e o colaborador - Estudo de caso: Hospital Albert Einstein. São Paulo, 2010. Dissertação (Mestrado em Hospitalidade) - Universidade Anhembi Morumbi, São Paulo, 2010.

GIL, A. C. Métodos e Técnicas de Pesquisa Social. 6. ed. São Paulo: Editora Atlas, 2008.

GODOI, A. F. de. Hotelaria hospitalar: humanização no atendimento em hospitais. 2. ed. São Paulo: Ícone, 2008.

LASHLEY, C; MORRISON, A. (2004). Em busca da hospitalidade: perspectivas para o mundo globalizado. Barueri, São Paulo: Manole.

MASCARENHAS, R. G. T; SOUZA, J. T. A qualidade percebida pelo paciente através dos serviços da hotelaria hospitalar: um estudo sobre a hospitalidade na área da saúde. Turismo \& Sociedade, v. 8, n. 3, p. 419-445. Curitiba-PR: 2015. Disponível em: <https://goo.gl/EmQ24z>. Acesso em 25 ago. 2016.

MAUSS, Marcel. Sociologia e antropologia. Tradução: Paulo Neves. São Paulo: Cosac \& Naify, 2003.

MEDEIROS, Cinthia P. C. Hospitalidade e Humanização: Mudanças na Realidade Hospitalar. Balneário Camboriú: UNIVALI, 2004. 
MIRSHAWKA, Victor. Hospital: fui bem atendido, a vez do Brasil. São Paulo: Makron Books, 1994.

PORTAL ALBERT EINSTEN. Pilares do Planetree. Disponível em:

$<$ https://goo.gl/GSA7b5>. Acesso em: 17 maio 2017.

QUEVEDO, M. F. Hospitalidade: Um estudo de caso do hospital Unimed Nordeste RS. 2006, 140 f. Dissertação (Mestrado em Turismo) - Universidade de Caxias do Sul, Caxias do Sul.

RIBEIRO, J. Hospitalidade em Serviços de Saúde Estudo de Caso Múltiplos: Hospital Geral do Grajaú, Ame Interlagos e Hospital Maternidade Interlagos. 2013, Dissertação (Mestrado em Hospitalidade) - Planejamento e Gestão Estratégica em Hospitalidade, Universidade Anhembi Morumbi. São Paulo, 2013.

TARABOULSI, F. A. Administração de Hotelaria Hospitalar: serviços aos clientes, humanização do atendimento, departamentalização, gerenciamento, saúde e turismo, hospitalidade. 2. ed. São Paulo: Atlas, 2004.

TARABOUlSI, F. A. Administração de Hotelaria Hospitalar. 4. ed. São Paulo: Atlas, 2009.

VERBIST, Cinthia Fusquine. A gestão da hospitalidade sob a perspectiva da humanização dos hospitais: um estudo de caso. 2014. Tese de Doutorado.

Artigo recebido em: 01/04/2019

Avaliado em: 26/06/2019

Aprovado em: 12/08/2019 